5. Hook EB, Regal RR (1995) Capture-recapture methods in epidemiology: methods and limitations. Epidemiol Rev 17: 243-264

6. Tuomilehto J, Karvonen M, Pitkaniemi J et al. (1999) Record-high incidence of Type I (insulin-dependent) diabetes mellitus in Finnish children. Diabetologia 42: 655-660
7. EURODIAB ACE Study Group (2000) Wide variability and increasing incidence of childhood diabetes in Europe. Lancet (in press)

8. Parslow R, McKinney PA, Law GR et al. (1997) Incidence of childhood diabetes mellitus in Yorkshire, northern England, is associated with nitrate in drinking water: an ecological analysis. Diabetologia 40: 550-556

\section{Vaccinations as risk factors for Type I diabetes mellitus}

\begin{abstract}
Dear Sir,
With much interest I have read the study 'Infections and vaccinations as risk factors for childhood Type I (insulin-dependent) diabetes mellitus' from the EURODIAB Substudy 2 Study Group [1]. The study shows that pre-school day-care attendance reduces the risk of Type I diabetes whereas vaccination had no notable effect. The outcome for day-care attendance seems clear. The outcome for vaccinations is, however, less so in my opinion. Some information is lacking, on which the authors hopefully can comment.

Vaccination is a challenge for the immune system with the aim of protecting the recipient against wild-type infection. On a population base, vaccination will also modify the epidemiological pattern of wild-type infection. Mass-vaccination reduces circulation of wild-type infection, resulting in a change from endemic to sporadic infections with incidental outbreaks. This is observed in some regions of the Netherlands where a minority population lives that refuses vaccination for religious reasons [2]. Such a change in epidemiology can have paradoxi-
\end{abstract}

Corresponding author: J.M.D. Galama, MD, PhD, Head of the Virology Section, Institute of Medical Microbiology, University Medical Center, Nijmegen, P. O. Box 9101, 6500 HB Nijmegen, The Netherlands cal and unintended effects because it results in postponement of infection to a later mean age [3].The ultimate outcome of mass-vaccination will be the establishment of herd-immunity with disappearance of the pathogen from the community and protection also for the non-immune, e.g. those who are not vaccinated. The authors did not incorporate such non-stochastic effects in their analyses, which probably will confound the outcome, at least for some of the vaccinations included. Such effects will furthermore hamper a proper comparison between the participating centres, which have their own history of immunisations and because of that will vary for the incidence of wild-type infections.

Yours sincerely,

J.M.D. Galama

\section{References}

1. The EURODIAB Substudy 2 Study Group (2000) Infections and vaccinations as risk factors for childhood Type I (insulin-dependent) diabetes mellitus: a multicentre casecontrol investigation. Diabetologia 43: 47-53

2. Oostvogel PM van Wijngaarden JK, van der Avoort HGAM et al. (1994) Poliomyelitis outbreak in an unvaccinated community in the Netherlands, 1992-1993. Lancet 344: 665-670

3. Van Druten JAM, de Boo Th Plantinga AD (1986) Measles, mumps and rubella: control by vaccination. Dev Biol Stand 65: 53-63
Dear Sir,

J.M.D. Galama asks if we can incorporate into our analysis information about indirect effects of vaccination such as the establishment of herd-immunity, the postponement of infection to later ages and the eradication of pathogens from the community. Clearly it would be very difficult to collect data on such factors in dispersed populations over the lengthy periods during which the children in our study were at risk of these infections. Because the children in our control groups were drawn from the same populations as those with Type I diabetes any indirect effects of vaccination might be expected to affect both diabetic and control subjects equally. We therefore argue that the conclusions from our comparisons of the two relate to the direct effects of vaccination and that any modifications to the epidemiology of infectious diseases produced by mass vaccination are unlikely to confound our comparisons. Although we agree that such indirect effects could have a role in explaining the large variation in incidence within Europe, we would point out that the purpose of our study was not to make comparisons between participating centres.

Sincerely, C. C. Patterson, G. Dahlquist, G. Soltész (on behalf of the EURODIAB Substudy 2 Study Group)
Corresponding author: Dr C. C. Patterson, Department of Epidemiology and Public Health, The Queen's University of Belfast, Royal Victoria Hospital, Grosvenor Road, Belfast BT12 6BJ, UK 